NBER WORKING PAPER SERIES

\title{
IDENTIFYING THE EFFICACY OF CENTRAL BANK INTERVENTIONS: THE AUSTRALIAN CASE
}

\author{
Jonathan Kearns \\ Roberto Rigobon \\ Working Paper 9062 \\ http://www.nber.org/papers/w9062 \\ NATIONAL BUREAU OF ECONOMIC RESEARCH \\ 1050 Massachusetts Avenue \\ Cambridge, MA 02138 \\ July 2002
}

The authors would like to thank participants at the MIT macroeconomics lunch, and Mathew Boge of the Reserve Bank of Australia for providing the data. The first author thanks the Reserve Bank of Australia for funding. The views expressed herein are those of the authors and not necessarily those of the National Bureau of Economic Research or the Reserve Bank of Australia.

(C) 2002 by Jonathan Kearns and Roberto Rigobon. All rights reserved. Short sections of text, not to exceed two paragraphs, may be quoted without explicit permission provided that full credit, including $\mathbb{C}$ notice, is given to the source. 
Identifying the Efficacy of Central Bank Interventions: The Australian Case

Jonathan Kearns and Roberto Rigobon

NBER Working Paper No. 9062

July 2002

JEL No. F30

\begin{abstract}
The endogeneity of exchange rates and intervention has long plagued studies of the effectiveness of central banks actions in foreign exchange markets. Researchers have either excluded contemporaneous intervention, so that their explanators are predetermined, or obtained a small, and typically incorrectly signed, coefficient on contemporaneous intervention. Failing to account for the endogeneity, when central banks lean against the wind and trade strategically, will likely result in a large downward bias to the coefficient on contemporaneous intervention -- explaining the negative coefficient frequently obtained.

We use an alternative identification assumption, a change in Reserve Bank of Australia intervention policy, that allows us to estimate, using simulated GMM, a model that includes the contemporaneous impact of intervention. There are three main results. Our point estimates suggest that central bank intervention has a economically significant contemporaneous effect. A $\$$ US100m purchase of the domestic currency will appreciate the exchange rate by 1.35 to 1.81 per cent. This estimate is remarkably similar to the calibration conducted by Dominguez and Frankel (1993), who themselves noted their estimate was larger than previous empirical findings. Secondly, the vast majority of the effect of an intervention on the exchange rate is found to occur during the day in which it is conducted, with only a smaller impact on subsequent days. Finally, we confirm findings that Australian central bank intervention policy can be characterized by leaning aginst the wind.
\end{abstract}

Jonathan Kearns

MIT, E52-243d

50 Memorial Drive

Cambridge, MA 02142

jkearns@mit.edu
Roberto Rigobon

MIT, E52-434

50 Memorial Drive

Cambridge, MA 02142

and NBER

rigobon@mit.edu 


\section{Introduction}

Since the introduction of floating exchange rates the use, and efficacy, of intervention in the foreign exchange market has been a controversial topic. Most central banks have at times engaged in frequent intervention, and at other times followed a more laissez faire approach to the exchange rate. ${ }^{1}$ No doubt the observed disparate range of policies between central banks, and within individual central banks over time, can in part be attributed to the lack of accord on the effectiveness and consequences of central bank intervention. Two key questions remain unresolved: how effective is foreign exchange intervention, and, if it is effective, through which channel does it act?

A critical barrier to answering these questions has been overcoming the endogeneity of changes in the exchange rate and intervention. The central hypothesis is that intervention changes the exchange rate. But at the same time, the decision to intervene is not independent of the movements in the exchange rate. Moreover, even once a central bank has decided to intervene, the quantity of currency it buys or sells will typically depend on the response of the exchange rate to its trades.

The literature has typically dealt with the simultaneous equations problem by assuming that the contemporaneous decision of the central bank is independent of the current innovations to the exchange rate. This is a strong assumption. For example, it assumes that the central bank does not change its selling or buying behavior by assessing the impact its actions have had on the exchange rate. On the other hand, there is strong evidence in stock markets that big players indeed act strategically when they are unwinding large positions. Therefore, why should we expect the same behavior is not optimal for a central bank?

In this paper we use an alternative identification method to solve the problem of simultaneous equations. We use daily Reserve Bank of Australia (RBA) interventions data over the period 1986 to 1993, which contains a dramatic change in intervention policy that we use for identification. We show that the estimates we obtain have the correct sign and are significantly larger than those found with more standard methods. This is exactly the direction we would have expected if endogenous variables is an important source of the bias. Further, the vast majority of the effect of an intervention on the exchange rate is found to occur during the day in which it is conducted with a smaller impact on subsequent days. This explains why small effects are usually found when lag values are used in the typical OLS specifications. The major contribution of this paper is to provide some evidence on the contemporaneous effectiveness of intervention. Although, our methodology does not indicate the channels through which intervention operates, it provides an improvement from previous estimates obtained in the literature.

We concentrate our analysis on sterilized interventions, but we do not distinguish between secret and public interventions. While undoubtedly this is an important distinction, most and in particular the largest, interventions are public. Certainly, future research should reconsider this issue. In this paper the focus of our attention is the estimation problem. Indeed, we think that the simultaneous equations problem is the crucial aspect limiting our understanding of how effective policy is.

The identification assumption we use is based on the fact that the RBA (in 1991) decided to change their policy regarding foreign exchange rate interventions. We interpret this shift in policy as exogenous, which is

\footnotetext{
${ }^{1}$ Schwartz (2000) suggests that intervention is a dying practice despite the continued use of active intervention by the ECB and Bank of Japan. However, the 18 central banks that responded to a survey reported in Neely (2001) believe it affects the exchange rate. Traders' survey responses in Cheung and Wong (2000) indicate they also believe intervention has an effect on exchange rates.
} 
an important ingredient in our solution to the problem. Other countries have also changed "exogenously" their policies, but typically central banks endogenously respond to the conditions in the market. Again, future research should endogenize the policy decision and extend the present analysis to deal with more general framework. However, as is argued in the text below it is the case that the Australian central bank decision to change their method of intervention is unrelated to other macro events.

The paper proceeds as follows. There is a brief discussion, in Section II, of central bank intervention and the associated literature. A description of the data and discussion of RBA intervention follow this, in Section III. Section IV presents the estimation method used in this study. The results are presented in Section V, followed by conclusions.

\section{Review of the literature on Central bank intervention.}

This section briefly reviews the literature on central bank intervention, focussing on the simultaneous relationship between, and temporal behavior of, exchange rate returns and intervention. For more general and extensive reviews see Sarno and Taylor (2001), Dominguez and Frankel (1993b) and Edison (1993).(Sarno and Taylor, 2001)(Edison, 1993)

Empirical studies, and statements by central banks, suggest that central banks intervene in foreign exchange markets to slow or correct excessive trends in the exchange rate, i.e. they "lean against the wind", and to calm disorderly markets (for example Lewis (1995b) and Baillie and Osterberg (1997b)). ${ }^{2}$ The survey responses of central banks in Neely (2001) suggest that these factors continue to drive the decision to intervene. A recent study for Australia by Kim and Sheen (2000) has similar conclusions. Importantly, when central banks intervene they trade in blocks throughout the day. As Neely (2001) reports, their subsequent trades are conditional on the response of the exchange rate to their earlier trades.

Two main channels have been suggested through which sterilized intervention can affect the level of the exchange rate: the portfolio balance channel and the signalling channel. Intervention changes the exchange rate through the portfolio balance channel if government bonds are imperfect substitutes, and so the change in the reserve asset holdings of a central bank results in private investors revaluing their portfolios of domestic and foreign assets. ${ }^{3}$ Since interventions are small relative to the stock of outstanding bonds most authors, including Rogoff (1984), have expressed skepticism that intervention could have a large impact through the portfolio balance channel. Not surprisingly, many studies do not find evidence of this channel, and those that do, such as Dominguez and Frankel (1993b), Evans and Lyons (2001) and Ghosh (1992), suggest that it is weak. ${ }^{4}$

Mussa (1981) suggested that if the central bank uses foreign exchange interventions to credibly indicate intended changes in monetary policy, the resulting revaluing of the exchange rate can be described as the signaling channel. The impact of intervention through the signaling channel has often been found to be substantially stronger than through the portfolio balance channel (for example Dominguez and Frankel (1993b)). For the signalling channel to be an ongoing transmission mechanism central banks should be seen to follow interventions

\footnotetext{
${ }^{2}$ Other reasons occasionally cited by central banks include to target particular exchange rates, or to support other central banks. We do not explicitly consider the impact of intervention on conditional exchange rate volatility, see Rogers and Siklos (2001) for Australia or more generally Dominguez (1998) and Bonser-Neal and Tanner (1996).

${ }^{3}$ The portfolio balance channel requires not only that bonds are imperfect substitutes, but also the failure of Ricardian equivalence.

${ }^{4}$ Dominguez and Frankel (1993c) and Evans and Lyons (2001) both assess the portfolio balance channel for unsterilized intervention and so provide upperbound estimates for the impact of sterilized intervention.
} 
with appropriate changes in monetary policy. As a result intervention operating through the signaling channel does not constitute an independent policy tool. Despite the evidence of a signaling channel, Fatum and Hutchison (1999) are unable to find an explicit link between intervention and future monetary policy, while Lewis (1995b) and Kaminsky and Lewis (1996) suggest it occasionally operates in the wrong direction.

Most central banks do not publicly announce their interventions. ${ }^{5}$ In light of the evidence for a signaling channel many authors have questioned this policy. ${ }^{6}$ But interventions are not completely secret. Dominguez and Frankel (1993b) find that most, and particularly the largest, interventions are reported. Central banks can choose the method of intervention, ranging from direct trades with commercial banks, to indirect trades through brokers, to control the degree of secrecy of their actions.

If intervention operates through the signaling channel then the exchange rate should react as soon as traders digest the information contained within the intervention. Goodhart and Hesse (1993), Peiers (1997), Dominguez (1999) and Chang and Taylor (1998) find that interventions that are intended to be visible are typically reported by news services within 10 minutes to 2 hours, by which time it is often no longer 'news' to traders. Any effect through the portfolio balance channel is also likely to be rapid as bond holders quickly respond to the change in the relative supplies in the highly liquid market for government securities. Indeed, Neely (2001) reports that the majority of central banks believe the full effects of intervention are reflected in the exchange rate within a matter of hours.

Despite the evidence of the rapid response of the exchange rate to intervention, studies using daily data have often abstracted from the endogeneity of intervention and exchange rate determination by only including lagged intervention (for example Baillie and Osterberg (1997a) and Lewis (1995b)). While intervention may still have an effect on the days subsequent to the initial trades, omitting the contemporaneous intervention prevents measurement of the immediate impact and is likely to bias other coefficient estimates. Other studies that include contemporaneous intervention, such as Kaminsky and Lewis (1996) and Kim et al (2001), typically obtain an incorrectly signed contemporaneous coefficient, suggesting that purchases of the domestic currency cause it to depreciate. Seemingly what they capture is the policy function coefficient that represents central banks' tendency to "lean against the wind". The insignificant and incorrectly signed coefficients in many previous studies indicate that an accurate estimation of the impact of intervention on the exchange rate must incorporate the contemporaneous effect, and account for the endogeneity between these variables.

\section{Reserve Bank of Australia Intervention Data}

The estimation in this study uses daily interventions in the foreign exchange market by the RBA over the period from July 1986 to November 1993. This period is chosen because it contains a single distinct change in intervention policy, in October 1991, that allows us to identify the parameters in our exchange rate and intervention system. Additionally, the characteristics of intervention in this sample facilitate accurate estimation. Over the 7 years of data (1,930 daily observations) intervention is frequent (48 per cent of days) and often large (up to $\$$ A1.3 billion). Another advantage of our sample is that other central banks do not intervene in the USD/AUD market and so we need only focus on the actions of one central bank.

\footnotetext{
${ }^{5}$ One exception is the Swiss National Bank as noted by Fischer and Zurlinden (1999).

${ }^{6}$ Alternatively, Bhattacharya and Weller (1997) and Vitale (1999) develop models of intervention that rationalize secrecy about interventions.
} 
The data are the daily net purchases of Australian dollars by the RBA and include all transactions made by the RBA, including those on behalf of the Government. Since the RBA can, and does, meet the Government's demand for foreign currency transactions from its own reserves, it has discretion as to the timing of transactions on behalf of the Government. For this reason the inability to exclude transactions on behalf of the Government does not appear to be problematic. Similarly, Neely (1998) argues that not excluding client transactions for the Fed has little influence. Over the sample used, almost all RBA intervention were conducted in the spot market verses the US dollar (Andrew and Broadbent (1994)). ${ }^{7}$ Rankin (1998) reports that the RBA has always sterilized its interventions. ${ }^{8}$

The exchange rate is measured as the US dollar value of an Australian dollar (USD/AUD). The intervention and exchange rate returns data are aligned to cover exactly the same 24-hour period, commencing at 9am Sydney time. This avoids inaccurate results from using misaligned data, which have potentially hampered previous studies on central bank intervention. Aligning the intervention and exchange rate returns data is important since central banks can, and do, intervene outside their business hours, as shown in Dominguez (1999), and stated for the RBA by Rankin (1998). ${ }^{9}$ The 24 -hour period over which the data are measured will be referred to as a day. The intervention data for any given day will include transactions conducted in any of the major markets around the world on that calendar day. ${ }^{10}$

Rankin (1998) outlines five distinct periods of intervention policy used by the RBA since the float of the Australian dollar in December 1983. Table 1 summarizes the pattern of intervention over these five episodes. The two periods used in this study are the second and third. During the period immediately following the float of the Australian dollar, December 1983 to June 1986, the RBA allowed the dollar to float freely with only very small interventions. Our study commences using data from July 1986 when the RBA took on a distinctly proactive policy to foreign exchange market intervention. Interventions became more frequent (the RBA was active on 69 per cent of days) and substantially larger (the average absolute intervention was $\$$ A63 million). The change in policy in our sample occurs in October 1991 when the RBA all but ceased to make very small interventions. Large interventions continued to be used as in the preceding era as seen in Figure 1. As a result, the frequency of interventions was drastically reduced (to 24 per cent of days), and the average size of interventions increased substantially (to $\$$ A144 million). We do not consider the last two episodes when the RBA did not intervene from December 1995 to June 1995, or when interventions resumed in July 1995.

\section{[Insert Figure 1 here] \\ [Insert Table 1 here]}

Table 2, drawn largely from Neely (2001), compares the frequency and size of RBA interventions with those of the Fed, the Bundesbank, and the Swiss National Bank. Over the period covered in the table, from the early 1980 s to the end of the 1990s, the RBA intervened on 42 per cent of days, compared to between 4 and 12.5 per

\footnotetext{
${ }^{7}$ Over the past decade the RBA has moved to using a combination of spot maket transactions and currency swaps, which together replicate a forward, to intervene and sterilize their intervention (see Rankin (1998)).

${ }^{8}$ Dominguez and Frankel (1993b) and the references contained therein, suggest the Fed, Bundesbank and Bank of Japan have typically only partially sterilized their interventions.

${ }^{9}$ Given Australian trading hours do not overlap with either London or New York trading hours, and BIS (1993) shows one-quarter of Australian dollar trading occurs in markets outside of Australian trading hours, this is potentially important.

${ }^{10}$ For a few 24 hour periods that end on an Australian public holiday we do not have an observation in the Sydney 9am exchange rate series. Instead the Australian dollar exchange rate measured at 12 EST (2am or 4am Sydney time, depending on daylight saving) by the New York Fed is used.
} 
cent for the other central banks. Typical central bank interventions are tiny relative to the huge daily turnover in foreign exchange markets. The daily turnover in the USD/AUD market was estimated to be \$US17.9 billion in 1992 by BIS (1993), although only $\$$ US4.8 billion of this involved a non-financial counterparty ${ }^{11}$ While the Australian economy is substantially smaller than the US and German economies, and the Australian dollar less heavily traded than all three other currencies in Table 2, the RBA interventions are of a comparable size to those of the larger central banks. ${ }^{12}$ The large magnitude of some RBA interventions is also confirmed by comparing the maximum interventions to the money base and M1 in Table 1. In the two episodes considered in this study, the largest intervention is seen to be over 5 per cent of the money base, or 2 per cent of M1. Note that while the turnover in the foreign exchange market has increased substantially, and certainly did so through our sample, neither of the hypothesized transmission channels are affected by the volume of turnover.

[Insert Table 2 here]

\section{Identification of the effectiveness of foreign exchange rate inter- vention}

In this section we use a simple model of central bank intervention to highlight the limitations of the standard methods and to show how we solve the identification problem.

The manner in which intervention affects the exchange rate can be seen from a generalized uncovered interest parity (UIP) relationship

$$
e_{t}=E\left\{e_{t+1} \mid \Omega_{t}\right\}+i_{t}-i_{t}^{*}+\eta_{t}
$$

where $e_{t}$ is the exchange rate (value of domestic currency), $\eta_{t}$ represents possible predictable deviations from UIP, and $\Omega_{t}$ is the time $t$ information set, which includes contemporaneous and past interventions, $\left\{I N T_{j}\right\}_{j=t}^{-\infty} \subset \Omega_{t}$. Substituting forward this relationship, and suppressing other elements of the information set, the exchange rate is

$$
e_{t}=E\left\{\sum_{j=0}^{T-1}\left[i_{i+j}-i_{t+j}^{*}+\eta_{t+j}\right] \mid I N T_{t}\right\}+e_{t+T}
$$

where $e_{t+T}$ is the exchange rate at some distant point in the future. Under the portfolio balance channel, the relative supplies of domestic and foreign bonds changes so that the risk premium on domestic assets, which is part of $\eta_{t}$, changes. This is then seen to affect the current exchange rate. The signalling channel suggests that interventions are a commitment to future monetary policy and so represent a change in the expected future interest rate, $E\left\{i_{t+j} \mid I N T_{t}\right\}$, so changing the current exchange rate. Under either channel the exchange rate is a function of contemporaneous intervention, $e_{t}=e_{t}\left(I N T_{t}\right)$.

As noted earlier, central banks typically state that they intervene to slow or correct excessive trends in the exchange rate and to calm disorderly markets. Indeed, the governor of the RBA states that the RBA has used

\footnotetext{
${ }^{11}$ The average (absolute) intervention for the regime including 1992 was just 0.6 per cent of the total average daily turnover.

12 The BIS survey lists the USD/AUD currency pair as the 9th most traded. The average daily turnover for the USD/DEM, USD/JPY and USD/CHF were \$US192.2b, \$US154.8b, and \$US48.8b. Only considering trades with non-financial counterparties the USD/AUD was the fifth most traded currency pair with the three pairs mentioned before respectively $\$$ US26.9b, $\$$ US32.3b, \$US7.0b.
} 
intervention in "circumstances where market imperfections are resulting in overshooting" and that "intervention can play a useful role in limiting extreme movements in the exchange rate" (Macfarlane (1998)). Since the RBA sterilizes interventions, and is acknowledged to allow the Australian dollar to float quite freely, it seems reasonable to assume that intervention is not used as a separate policy tool with independent goals. Rather, intervention is focused on exchange rate outcomes. A simple representation of this policy, as used in Almekinders and Eijffinger (1996), is that the central bank's preferred level of intervention, or shadow intervention, $I N T^{*}$, would minimize squared deviations of the exchange rate from a moving target.

$$
L=\left(e_{t}\left(I N T_{t}^{*}\right)-\bar{e}_{t}\right)^{2}
$$

Given the central bank is allowing the exchange rate to float, but doesn't want it to move 'too quickly', the target is taken to be a moving average of past values of the exchange rate, $\bar{e}_{t}=\frac{1}{n} \sum_{j=1}^{n} e_{t-j}$. The optimal level of intervention will then by given by

$$
\begin{aligned}
e_{t}\left(I N T_{t}^{*}\right)-\bar{e}_{t} & =0 \\
\Delta e_{t}\left(I N T_{t}^{*}\right) & =-\sum_{j=1}^{n-1}\left(\frac{n-j}{n}\right) \Delta e_{t-j}
\end{aligned}
$$

However, central banks do not intervene on every day, and very small interventions are extremely rare. Presumably there are some costs to intervention, possibly because the strength of signals is reduced if they are used too frequently. As a result the central bank only intervenes if the loss function would exceed some benchmark, or equivalently if the shadow intervention exceeds a given threshold, otherwise remaining absent from the market. Actual intervention can then be represented as

$$
I N T_{t}=\Im\left(\left|I N T_{t}^{*}\right|>\overline{I N T}\right) \cdot I N T_{t}^{*}
$$

where $\Im()$ is the indicator function.

Equations (2), (5) and (6) constitute a system that determine the exchange rate and intervention.

\subsection{Setup of the estimation system}

We generalize the previous framework to include unobservable variables that affect the exchange rate and the central bank's decision for intervention. The reason behind this extension is that we believe that there are factors that are unobservable at daily frequencies that have impact on both variables, such as liquidity shocks, macro shocks, etc. The model used is:

$$
\begin{aligned}
\Delta e_{t} & =\alpha I N T_{t}+\gamma z_{t}+\varepsilon_{t} \\
I N T_{t} & =\Im\left(\left|I N T_{t}^{*}\right|>\overline{I N T}\right) \cdot I N T_{t}^{*} \\
I N T_{t}^{*} & =\beta \Delta e_{t}+z_{t}+\eta_{t}
\end{aligned}
$$

$\Delta e_{t}$ is the observed exchange rate return at date $t$ (a positive value is an appreciation), $I N T_{t}$ is the observed intervention (positive values are purchases of the domestic currency), and $I N T_{t}^{*}$ is a shadow intervention. The 
estimation procedure includes constants and potentially lags, but this simple version is sufficient to demonstrate the endogeneity problem.

Equation (7) is the reaction of the exchange rate to the central bank intervention. We assume that the exchange rate is affected by two types of shocks: $\varepsilon_{t}$ which is a pure idiosyncratic shock to the exchange rate, which we assume has no direct impact on the intervention decision, and a common shock $\left(z_{t}\right)$ which is assumed to move both the exchange rate and the central bank intervention decision. We explore the interpretation of these shocks below.

Equation (8) is the decision of the central bank to intervene or not. We assume that this decision is made entirely based on the shadow intervention. In other words, if the required intervention is large (larger in absolute terms than some threshold $\overline{I N T}$ ) then the central bank participates in the market, otherwise, it remains absent. Observe that implicitly we assume that if the shadow intervention is larger than the threshold then the central bank intervenes, and its intervention is exactly the shadow one.

Equation (9) determines the shadow intervention. We assume that it is affected by the movements in the exchange rate, by the aggregate or common shock, and by some idiosyncratic shock reflecting innovations to exchange rate policy. If the central bank aims to offset changes in the exchange rate, i.e. lean against the wind, then $\beta$ will be negative. Equations (8) and (9) together constitute the central bank's reaction function; where the former reflects the decision to intervene, and the later one determines the quantity, or size of intervention.

The policy shock $\left(\eta_{t}\right)$ is interpreted as innovations in the exchange rate target that are independent of the nominal exchange rate shocks $\left(\varepsilon_{t}\right)$ and the common shock $\left(z_{t}\right)$. The idea is to separate idiosyncratic shocks to policy (such as trades on behalf of the government or unwinding of positions) and to the exchange rate (for example, economic fundamentals) from those shocks that we might expect to affect both variables (such as herding, liquidity, or shocks to the exchange rate during periods of high conditional volatility). These common shocks will affect how intervention takes place, and the exchange rate at the same time. We assume that these shocks are i.i.d., with mean zero and variances $\sigma_{\varepsilon}, \sigma_{\eta}$, and $\sigma_{z}$. For simplicity in the exposition we have assumed that all the variables have zero mean, but in the empirical implementation it is important to include constants.

Finally, the parameter of interest is $\alpha$. If central bank intervention is effective, then purchases of the domestic currency will appreciate the currency and so $\alpha$ will be positive.

The intuition for this model is that the central bank leans against the wind, so $\beta<0$, either to slow deviations from trend, or to calm volatile markets. Small changes are tolerable and so the central bank does not bother intervening. On the other hand, if exchange rate returns would otherwise be large, larger interventions would be required to counteract these and will cause the central bank to enter the market. The shadow intervention $\left(I N T_{t}^{*}\right)$ summarizes the expected intervention if the central bank were to trade continuously in the foreign exchange rate market.

This simple framework captures the two sources of simultaneity that exist in the data. The first one, is the endogenous decision of participation. The second one, is the size of the intervention and the change in the exchange rate once the decision of participation has been made. While the first source of bias has been widely acknowledged in the literature, the second has received very little attention. This is understandable. Finding instruments for the first one is hard, but some might be available. For the second one, this is much more difficult.

In this model there does not exist an instrument that can be used to solve the problem of simultaneous equations. More importantly, this bias is likely to be negative, pushing the estimate of $\alpha$ in equation (7) downward, possibly even negative, explaining most of the results found in the data. 
It is important to mention that there are several aspects of central bank intervention that have been oversimplified in this model. First, there is no distinction between public and secret interventions. As was mentioned before, this has received considerable attention in the literature. In this paper we focus on the estimation problem. Second, we do not attempt to distinguish between sterilized and unsterilized interventions as the RBA states that all of its interventions are sterilized.

\subsection{Identification through changes in intervention policy.}

The problem of identification is easily shown by counting the number of unknowns, and the number of series we can measure, in the model. Under the assumption that we only observe the exchange rate, the size of the intervention, and its timing, then, aside from the means, we can compute only five moments from the data: the probability (or frequency) of intervention, the variance of the exchange rate when there is no intervention, and the covariance matrix when an intervention has taken place. However, in the model there are seven unknown coefficients that explain the behavior of such variables: the parameters of interest $(\alpha, \beta$, and $\gamma)$, the threshold of intervention $(\overline{I N T})$ and the three variances $\left(\sigma_{\varepsilon}, \sigma_{\eta}\right.$, and $\left.\sigma_{z}\right) .{ }^{13}$

The standard procedures in the literature use the following assumptions. First, that there are good instruments for the participation decision. Second, that either $\beta=0$ or $\alpha=0$ (exclusion restrictions). And third, that the instrument is correlated with $\eta_{t}$ but not with $z_{t}$. This set of assumptions seems rather strong. Central banks no doubt intervene based on their most recent information set, which includes the change in the exchange rate during the day. Further, the fact that central banks know they have market power, which is the whole rationale why they think it is worth intervening in the first place, collides with the assumption that $\beta$ is zero. Central banks should be, and indeed are, strategic in their interventions. The alternative identification assumption that $\alpha=0$ is similarly problematic in that it implies that central bank interventions don't have any effect on the day during which they are conducted. This contradicts significant circumstantial evidence.

The main contribution of this paper, is to relax these set of assumptions and use an alternative identification method that can deal with some of the econometric issues at hand. Obviously, we depend on another set of assumptions. We think those are weaker, in the sense that most of them are already imposed in the standard literature. But this is certainly the first pass at the problem using these alternative methods and further research should extend the present procedure. We discuss the caveats in detail at the end.

Our identification procedure is quite simple; in September 1991, the RBA changed its foreign exchange rate intervention policy. Following the change, the RBA all but ceased to conduct small interventions but continued to undertake larger interventions as before the change. In the model this would be summarized by a shift in $\overline{I N T}$. Effectively, this means that there are two regimes. Under the assumption that the parameters and the variance of the shocks remain the same across both regimes, we have only eight unknowns (one more than before because we have two thresholds) but at least ten moments in the data.

Specifically, the basic model we estimate is the following:

\footnotetext{
${ }^{13}$ The estimation of means adds the same number of equations and unknowns to the system, thus, the problem of underidentification remains the same.
} 


$$
\begin{aligned}
& \Delta e_{t}=c_{e} \quad+\alpha I N T_{t} \quad+\gamma z_{t} \quad+\varepsilon_{t} \\
& I N T_{t}^{*}=\begin{array}{lll}
c_{I N T}+\beta \Delta e_{t} & +z_{t} & +\eta_{t}
\end{array} \\
& I N T_{t}= \begin{cases}\Im\left(\left|I N T_{t}^{*}-c_{I N T}\right|>\overline{I N T_{l}}\right) \cdot I N T_{t}^{*} & t<\hat{t} \\
\Im\left(\left|I N T_{t}^{*}-c_{I N T}\right|>\overline{I N T_{h}}\right) \cdot I N T_{t}^{*} & t>\hat{t}\end{cases}
\end{aligned}
$$

Note that in this setup we allow for constants in the mean equations and below we extend the model to also include lags. ${ }^{14}$

We estimate this model with, and without, lags and present both results. When the model is estimated without lags, there are eleven parameters of interest:

$$
\left\{c_{e}, c_{I N T}, \alpha, \beta, \gamma, \pi, \overline{I N T_{l}}, \overline{I N T_{h}}, \sigma_{\varepsilon}, \sigma_{\eta}, \sigma_{z}\right\}
$$

We compute the following moments in each of the regimes: the proportion of days with intervention; the mean exchange rate return; the mean intervention; the variance of the exchange rate on days with no intervention; and, the variance-covariance matrix on days with intervention. Furthermore, we compute the moments related to the serial correlation of the exchange rate, as well as the probability of consecutive interventions. This gives us a total of 20 moments, greater than the number of parameters, leaving our system over-identified.

We use simulated GMM to estimate the model. The general idea of this procedure can be easily understood by analyzing how other techniques estimate the coefficients. For example, when we use Maximum Likelihood the goal is to estimate the parameters using the mean and the variances. GMM extends that procedure and uses other moments. Simulated GMM is a further generalization, in which we choose different moments and characteristics from the data, and "create" our own data using our auxiliary model to match those "moments". Indeed, all three techniques use auxiliary models for their estimation. On the one hand, in ML we use multinomial distributions, described only by means and variances. On the other hand, simulated GMM creates its own data within a well specified model to produce the statistics that we are interested in matching from the population.

In summary, the procedure is as follows: First, we create random draws of 20,000 observations for three uncorrelated shocks with unitary variance. The same set of shock variables are retained for the entire estimation procedure. Second, we simulate the model given some initial conditions. Third, we compute the moments in the simulated data and compare them with the sample moments. Finally, we iterate this procedure to search for the coefficients that minimize the distance between the population moments and the simulated ones.

To calculate the standard errors of the estimates we use the asymptotic distribution of the sample moments. Using the data, we bootstrap the exchange rate, intervention, and probabilities of interventions to produce a sequence of moments (100 of them). Then we estimate the coefficients for each draw of the moments, computing the distribution of our coefficients. Because it is likely that the data is serially correlated, the bootstrap takes this into account.

\footnotetext{
${ }^{14}$ The lag structure takes into account that the exchange rate can only depend on observable variables. Thus, the lag of intervention used is $I N T_{t-1}$ and not $I N T_{t-1}^{*}$. However, for the shadow intervention equation we allow it to depend on the lag shadow realization.
} 


\section{Results}

Before we present our results, it is illustrating to demonstrate the problems in estimation that arise from using more traditional methods. As noted earlier, frequently, researchers exclude the contemporaneous impact of intervention in an attempt to overcome the endogeneity. To account for the properties of exchange rate data, a GARCH error structure is typically used. Table 3 presents the results from an EGARCH(1,1) model of $\log$ changes in the USD/AUD exchange rate over the full sample, and in each of the high and low bound regimes. To highlight the impact of the simultaneity bias, we also present regressions that include the contemporaneous intervention. The coefficients on lagged intervention are uniformly small (around 0.005), and frequently the wrong sign, suggesting that RBA purchases of Australian dollars depreciated the exchange rate.

[Insert Table 3 here]

The coefficient on contemporaneous intervention is always significant and incorrectly signed. The estimates are around -0.016 which in absolute value is much larger than the coefficients from the lag intervention. The wrong sign is a direct consequence of the endogeneity. The OLS estimate is a combination of $\alpha$ and $\beta$, and likely $\gamma$, and can be negative even for positive $\alpha$ if the RBA leans against the wind $(\beta<0)$, or common shocks affect the two equations with different signs $(\gamma<0) .{ }^{15}$

\subsection{Contemporaneous effects of Central Bank Intervention}

We now move on to the results from our basic model (equation (10)) that excludes lags. This implies that the central bank target is the previous day's exchange rate, although the rich error structure will capture deviations from this. Later we extend the model to include lags that implies a target of a longer moving average.

In Table 4 we report the coefficients of interest: $\alpha, \beta, \gamma$, the two thresholds, the constants and the variances. The first column is the point estimate using the simulated GMM methodology and the moments from the data. The second column is the mean of the bootstrapped distribution of the parameter. As mentioned before, we generate 100 sets of moments bootstrapping the residuals of the original data in each of the regimes. The standard deviation is of the boostrapped distribution of parameter estimates. The fourth column is the quasi t-statistic calculated as the mean divided by the standard deviation. It is important to highlight that the distributions are not normal, so this statistic should be considered informative, but not conclusive in terms of the significance of the coefficients. The fifth and sixth column are the maximum and minimum value of the boostrapped estimates. The last column is the percentage of the observations that are below zero. This is the statistic that we use to determine the significance of the coefficients. We prefer to look at the mass above and below zero rather than the quasi t-statistic given that most of the estimates are not normally distributed (this is a p-value).

[Insert Table 4 here]

Our main focus is on the estimate of $\alpha$. The point estimate is 0.135 , and the mean of the distribution is 0.136 . The standard deviation is 0.037 . Indeed, as can be seen, from all 100 realizations the minimum is 0.033 , which

\footnotetext{
${ }^{15}$ If there are no lags in the system the the OLS estimate when the exchange rate return is regressed on intervention will be $\frac{(\alpha+\gamma)(\alpha \beta+1) \sigma_{z}^{2}+\beta \sigma_{\varepsilon}^{2}+\alpha \sigma_{\eta}^{2}}{(\alpha \beta+1)^{2} \sigma_{z}^{2}+\beta^{2} \sigma_{\varepsilon}^{2}+\sigma_{\eta}^{2}}$
} 
implies that there is no mass below zero. Both the quasi t-statistic and the proportion of realizations below zero indicate that the estimate is highly significant. The distribution of $\alpha$ is shown in Figure 2.

[Insert Figure 2 here]

This estimate of $\alpha$ indicates that intervention has a large effect on the exchange rate. The coefficient on contemporaneous intervention, $\alpha(0.136)$, implies that $\$ A 100 \mathrm{~m}$ of purchases of Australian dollars is associated (on average) with a 1.36 per cent appreciation of the Australian dollar. If we take the average exchange rate over our sample period to be 0.75 , then $\$$ US100m of purchases of Australian dollars would have appreciated the Australian dollar by approximately 1.81 per cent. This response is larger than most results in the literature but closely related to calibrations obtained by Dominguez and Frankel (1993c). Dominguez and Frankel calculated that \$US100m of purchases of US dollars would appreciate the US dollar by just under 1.6 per cent.

Our estimate differs from that in Dominguez and Frankel (1993c) in that it is calculated directly from exchange rate and intervention data. In constructing their estimate Dominguez and Frankel need to make several assumptions, such as mean-variance preferences of investors, and use expectations survey data and assets supplies data that are likely to contain measurement errors. The dependence on survey data also requires that they consider exchange rate returns over a longer horizon and so can't estimate the short-run impact of intervention. A significant improvement of our estimation methodology is that we are able to include both contemporaneous intervention and exchange rate returns to address the simultaneity. Nevertheless, our estimate is close to the one found by Dominguez and Frankel (1993c), and we cannot reject the hypothesis that they are different.

The point estimate of $\beta$ is -0.028 , with mean of -0.089 and a relatively large standard deviation of 0.095 . As can be seen in Table 4 the quasi t-statistics suggest that the estimate is not statistically significant from zero. However, demonstrating the importance of the non-normality of the distribution, all realizations are below zero indicating the estimate is highly significant. Figure 3 depicts the distribution of $\beta$. As can be seen, the distribution is not normal and there are some realizations that are relatively large (close to zero) but the distribution has a long left tail.

\section{[Insert Figure 3 here]}

The negative coefficient conforms with our priors, and RBA statements, that interventions are dictated by leaning against the wind. The point estimate implies that a one percent unexpected depreciation of the exchange rate leads the central bank to lean against the wind, buying 28 million Australian dollars in the foreign exchange market to slow the depreciation.

Our estimate of $\gamma$ is precisely estimated; it is negative and significant. The point estimate is -0.304 , almost identical to the mean of the bootstrapped distribution, -0.305 , while the standard deviation is 0.056 . In this case 100 percent of the bootstrapped estimates are negative, implying that the coefficient is significantly different from zero at high levels of significance. The negative sign of $\gamma$ demonstrates that shocks common to the exchange rate process and the central bank's reaction function simultaneously weaken (strengthen) the currency and increase (decrease) the central bank's desire to support the currency. Again this supports our priors of central bank policy. These shocks can be interpreted to be shocks to the exchange rate during periods of high conditional volatility which the central bank shows greater inclination to resist. The negative estimate of $\gamma$ provides an 
additional reason why failing to account for the simultaneity of exchange rate and intervention determination is likely to bias downward the impact of intervention on the exchange rate.

Finally, the estimates of the thresholds are highly significant and reasonable given what we have observed. These values have been scaled to simplify the estimation process. Their interpretation is that in the early period the central bank participates in the foreign exchange rate market when the shadow intervention is larger than $\$ \mathrm{~A} 3.2 \mathrm{~m}$, while in the later regime it intervenes if the required intervention is larger than $\$ \mathrm{~A} 18.5 \mathrm{~m}$.

\subsection{Dynamic impact of Central Bank Intervention.}

We now extend the model to allow for two lags in the structural equations. Doing so provides a richer representation of the policy function and allows us to examine the temporal impact of interventions on the exchange rate.

The expanded model is:

$$
\begin{aligned}
& \Delta e_{t}=c_{e}+\alpha I N T_{t}+ \\
& \lambda_{e e, 1} \Delta e_{t-1}+\lambda_{e I N T, 1} I N T_{t-1}+\lambda_{e e, 2} \Delta e_{t-2}+\lambda_{e I N T, 2} I N T_{t-2}+ \\
& \gamma z_{t}+\varepsilon_{t} \\
& I N T_{t}^{*}=c_{I N T}+\beta \Delta e_{t}+ \\
& \lambda_{I N T e, 1} \Delta e_{t-1}+\lambda_{I N T I N T, 1} I N T_{t-1}^{*}+\lambda_{I N T e, 2} \Delta e_{t-2}+\lambda_{I N T I N T, 2} I N T_{t-2}^{*}+ \\
& z_{t}+\eta_{t} \\
& I N T_{t}= \begin{cases}\Im\left(\left|I N T_{t}^{*}-c_{I N T}\right|>\overline{I N T}_{l}\right) \cdot I N T_{t}^{*} & t<\hat{t} \\
\Im\left(\left|I N T_{t}^{*}-c_{I N T}\right|>\overline{I N T_{h}}\right) \cdot I N T_{t}^{*} & t>\hat{t}\end{cases}
\end{aligned}
$$

where the additional coefficients are the $\lambda$ 's. There are 14 coefficients to be estimated. We expand the moments used in the estimation to include across time statistics: we include the probability of two and three consecutive interventions, and the first and second serial correlation in the exchange rate for both the high and low thresholds. ${ }^{16}$ The results from the estimation are shown in Table 5.

[Insert Table 5 here]

The estimates of $\alpha, \beta$ have the same signs as those in the base model. The coefficient $\alpha$ is smaller but the coefficients on lagged interventions, $\lambda_{e I N T, 1}$ and $\lambda_{e I N T, 2}$, are also positive, indicating that intervention continues to affect the exchange rate on the days subsequent to the intervention. Notably, these subsequent effects are smaller. The largest impact from an intervention occurs on the day it is conducted. The coefficient $\beta$ is again negative, though larger in magnitude. The importance of accounting for the endogenous relationship is highlighted by the much smaller role that exchange rate changes from previous days have in determining intervention, as seen by the small coefficients on lagged exchange rate returns. The coefficients on lagged intervention are negative

\footnotetext{
${ }^{16}$ We have run the simulation also including other moments such as the probability of two positive interventions, and the correlation in the quantities of two consecutive interventions. The results were not sensitive to these changes.
} 
due to the tendency of subsequent interventions to be smaller than the initial intervention. The bootstrapped distributions are depicted in Figures 6 and 7 .

\author{
[Insert Figure 6 here] \\ [Insert Figure 7 here]
}

The interpretation of the response of the exchange rate to intervention is complicated by the feedback between the variables in the presence of lags. Figure 4 shows the impulse response functions for the exchange rate in the model with lags and the base model without lags. The impulse responses for the two models are calculated ignoring the participation decision of the central bank. Since the coefficients in the policy function on lagged intervention are negative, abstracting from the participation decision implies the central bank will unwind its intervention on subsequent days. Empirically this does not occur demonstrating the importance of the interaction of the two components of the central bank policy function. The central bank almost never intervenes on opposite sides of the market on subsequent days. A third series on the graph incorporates the entry decision by restricting the central bank to remain absent from the market on the days following the initial intervention. Here the effect on subsequent days is shown to be larger, though still smaller than that on the initial day.

[Insert Figure 4 here]

The cumulative impact of intervention is shown in Figure 5. Note that the short lag structure used constrains that intervention has a permanent effect on the exchange rate. A long lag structure would be needed to capture the unwinding of the effects of intervention. Including many lags is not practical for the estimation method we employ and so we are unable to assess how long the effects of intervention last beyond a few days. The cumulative response of the exchange rate to intervention, after 2 to 3 days, is similar for the models including and excluding lags. In the model with lags $\$$ A100m $(\$ \mathrm{US} 100 \mathrm{~m})$ will appreciate the exchange rate by 1 per cent (1.35 per cent), slightly less than the 1.36 per cent (1.81 per cent) predicted by the model excluding lags.

[Insert Figure 5 here]

\title{
5.3 Caveats and further research
}

Before concluding, it is worth spending time discussing the robustness and validity of the procedure developed in this paper. Our estimation methodology has several caveats that should be addressed in future research. First, it does not distinguish through which channel intervention affects the exchange rate. Given the relative shifts in bonds in private hands is small, the portfolio balance channel is likely to play an insignificant role. Rather, the signalling channel, and possibly market microstructure effects, would seem to be responsible - but this is a conjecture, rather than a result.

Second, as it stands our methodology requires that the change in policy is truly exogenous. Finding such exogenous changes in policy for other countries may not be straight forward. However, it is possible to model 
the threshold in the participation equation as a function of macro variables, the exchange rate, and even the second moments of the endogenous variables. The procedure of estimation would be exactly the same as the one described here if the change in policy is thought as a shift in the coefficients in that equation. Furthermore, the participation decision could be rationalized as a switching Markov regime where the transition probabilities are function of the endogenous variables. The estimation of these models is beyond the scope of the present paper, and are left for future research. Nevertheless, it is important to mention that in this paper we have emphasized the identification issue, and our specification is a reduced form representation of these models where the shift in policy would be reflected in changes in the intervention decision equation.

Finally, our methodology assumes that the coefficients are stable across regimes (other than the threshold). This seems to be a reasonable assumption in the current study but may be more difficult to justify in other contexts. This criticism is akin to the application of the Lucas critique to models of monetary policy. Our framework is not entirely exempt from this critique, and therefore, conclusions from this analysis are subject to the caveat of the strength of these assumptions.

\section{Conclusion}

The endogeneity of exchange rates and intervention has long plagued studies of the effectiveness of central banks' actions in foreign exchange markets. Researchers have either excluded contemporaneous intervention, so that their explanators are predetermined, or obtained a small, and typically incorrectly signed, coefficient on contemporaneous intervention. Failing to account for the endogeneity, when central banks lean against the wind and trade strategically, will likely result in a large downward bias to the coefficient on contemporaneous intervention - explaining the negative coefficient frequently obtained.

This paper uses a novel identification assumption, a change in RBA intervention policy, that allows us to estimate a model that includes the contemporaneous impact of intervention. We use simulated GMM to estimate the model. There are three main results. Our point estimates suggest that central bank intervention has a substantial effect. We find that a (sterilized) purchase of $\$$ US100m of Australian dollars by the RBA would be associated with an appreciation of between 1.35 and 1.81 per cent. These estimates are remarkably similar to that in Dominguez and Frankel (1993c) even though our estimation methodology is completely different, depending on only exchange rate and intervention data. Second, an intervention is shown to have its largest

effect on the exchange rate on the day in which it is conducted, with smaller effects on subsequent days. This finding has not previously been demonstrated in the literature due to the problem of endogeneity, and confirms the beliefs of central banks of the immediacy of the efficacy of intervention. Finally, we confirm findings that Australian central bank intervention policy can be characterized by leaning aginst the wind. 


\section{References}

Almekinders, G. J. and Eijffinger, S. C. W. (1996). A friction model of daily bundesbank and federal reserve intervention. Journal of Banking and Finance, 20(8):1365-80.

Andrew, R. and Broadbent, J. (1994). Reserve bank operations in the foreign exchange market: Effectiveness and profitability. Reserve Bank of Australia Research Discussion Paper 9406.

Baillie, R. T. and Osterberg, W. P. (1997a). Central bank intervention and risk in the forward market. Journal of International Economics, 43:483-497.

Baillie, R. T. and Osterberg, W. P. (1997b). Why do central banks interveve? Journal of International Money and Finance, 16(6):909-919.

Bhattacharya, U. and Weller, P. (1997). The advantage to hiding one's hand: Speculation and central bank intervention in the foreign exchange market. Journal of Monetary Economics, 39:251-277.

BIS (1993). Central Bank Survey of Foreign Exchange and Derivatives Market Activity 1992. Bank of International Settlements, Basle.

Bonser-Neal, C. and Tanner, G. (1996). Central bank intervention and the volatility of foreign exchange rates: Evidence from the options market. Journal of International Money and Finance, 15(6):853-878.

Chang, Y. and Taylor, S. J. (1998). Intraday effects of foreign exchange intervention by the bank of japan. Journal of International Money and Finance, 17:191-210.

Cheung, Y.-W. and Wong, C. Y.-P. (2000). A survey of market practitionerš̌ views on exchange rate dynamics. Journal of International Economics, 51:401-419.

Dominguez, K. M. (1998). Central bank intervention and exchange rate volatility. Journal of International Money and Finance, 17:161-190.

Dominguez, K. M. (1999). The market microstructure of central bank intervention. NBER Working Paper 733\%.

Dominguez, K. M. and Frankel, J. A. (1993a). Does foreign-exchange intervention matter? the portfolio effect. American Economic Review, 83(5):1356-1369.

Dominguez, K. M. and Frankel, J. A. (1993b). Does foreign exchange intervention work? Institute of International Economics.

Dominguez, K. M. and Frankel, J. A. (1993c). Foreign exchange intervention: An empirical assessment. In Frankel, J. A., editor, On Exchange Rates, pages 327-345. MIT Press.

Edison, H. (1993). The Effectiveness of Central Bank Intervention: A Survey of the Post-1982 Literature. Special Papers on International Economics 18. Princeton University.

Evans, M. D. and Lyons, R. K. (2001). Portfolio balance, price impact, and secret intervention. NBER Working Paper 8356. 
Fatum, R. and Hutchison, M. (1999). Is intervention a signal of future monetary policy? evidence from the federal funds futures market. Journal of Money, Credit and Banking, 31(1):54-69.

Fischer, A. M. and Zurlinden, M. (1999). Exchange rate effects of central bank interventions: An analysis of transaction prices. The Economic Journal, 109:662-676.

Ghosh, A. R. (1992). Is it singalling? exchange intervention and the dollar-deutschemark rate. Journal of International Economics, 32:201-20.

Goodhart, C. A. E. and Hesse, T. (1993). Central bank forex intervention assessed in continuous time. Journal of International Money and Finance, 12:368-389.

Kaminsky, G. L. and Lewis, K. K. (1996). Does foreign exchange intervention signal future monetary policy? Journal of Monetary Economics, 37:285-312.

Kim, S.-J., Kortian, T., and Sheen, J. (2000). Central bank intervention and exchange rate volatility - australian evidence. Journal of International Financial Markets, Institutions and Money, 10(3-4):381-405.

Kim, S.-J. and Sheen, J. (2000). The determinants of foreign exchange intervention by central banks: Evidence from australia. University of Sydney, Working Paper 2000-01.

Lewis, K. K. (1995a). Are foreign exchange intervention and monetary policy related, and does it really matter? Journal of Business, 68(2):185-214.

Lewis, K. K. (1995b). Occasional intervention to target rates. American Economic Review, 84(5):691-715.

Macfarlane, I. (1998). Speech to asia pacific forex congress. Sydney.

Mussa, M. (1981). The role of official intervention. Group of Thirty Occasional Papers No. 6 New York: Group of Thirty.

Neely, C. J. (1998). Technical analysis and the profitability of u.s. foreign exchange intervention. Federal Reserve Bank of St. Louis Review, 80(4):3-17.

Neely, C. J. (2001). The practice of central bank intervention: Looking under the hood. Federal Reserve Bank of St. Louis Review, 83(3):1-10.

Peiers, B. (1997). Informed traders, intervention, and price leadership: A deeper view of the microstructure of the foreign exchange market. Journal of Finance, 42(4):1589-1614.

Rankin, B. (1998). The exchange rate and the reserve bank's role in the foreign exchange market. www.rba.gov.au.

Rogers, J. M. and Siklos, P. L. (2001). Foreign exchange market intervention in two small open economies: The canadian and australian experience. Journal of International Money and Finance, forethcoming:999.

Rogoff, K. (1984). On the effects of sterilized intervention: An analysis of weekly data. Journal of Monetary Economics, 14:133-50.

Sarno, L. and Taylor, M. (2001). Official intervention in the foreign exchange market: Is it effective and, if so, how does it work? Journal of Economic Literature, XXXIX:839-868. 
Schwartz, A. J. (2000). The rise and fall of foreign exchange market intervention. NBER Working Paper 7751.

Vitale, P. (1999). Sterilised central bank intervention in the foreign exchange market. Journal of International Economics, 49:245-267. 
Table 1: Summary Statistics of Interventions.

\begin{tabular}{|c|c|c|c|c|c|c|}
\hline Regime & $\begin{array}{c}\text { Full } \\
\text { Dec-83 } \\
\text { Jul-00 } \\
\end{array}$ & $\begin{array}{c}\text { I } \\
\text { Dec-83 } \\
\text { Jun-86 } \\
\end{array}$ & $\begin{array}{c}\text { II } \\
\text { Jul-86 } \\
\text { Sep-91 }\end{array}$ & $\begin{array}{c}\text { III } \\
\text { Oct-91 } \\
\text { Nov-93 } \\
\end{array}$ & $\begin{array}{c}\text { IV } \\
\text { Dec-93 } \\
\text { Jun-95 } \\
\end{array}$ & $\begin{array}{c}\text { V } \\
\text { Jul-95 } \\
\text { Jul-00 }\end{array}$ \\
\hline $\begin{array}{l}\text { Number of interventions } \\
\text { Sales } \\
\text { Purchases } \\
\text { Total number of days }\end{array}$ & $\begin{array}{r}1283 \\
504 \\
4219\end{array}$ & $\begin{array}{r}99 \\
230 \\
640\end{array}$ & $\begin{array}{r}780 \\
143 \\
1338\end{array}$ & $\begin{array}{r}15 \\
116 \\
554\end{array}$ & $\begin{array}{r}0 \\
0 \\
397\end{array}$ & $\begin{array}{r}389 \\
15 \\
1290\end{array}$ \\
\hline $\begin{array}{l}\text { Probability of intervention } \\
\text { Unconditional } \\
\text { Conditional on } I N T_{t-1} \neq 0 \\
\text { Conditional on } I N T_{t-1}=0\end{array}$ & $\begin{array}{l}0.42 \\
0.73 \\
0.20\end{array}$ & $\begin{array}{l}0.51 \\
0.62 \\
0.40\end{array}$ & $\begin{array}{l}0.69 \\
0.80 \\
0.44\end{array}$ & $\begin{array}{l}0.24 \\
0.50 \\
0.15\end{array}$ & 0 & $\begin{array}{l}0.31 \\
0.75 \\
0.12\end{array}$ \\
\hline $\begin{array}{l}\text { Average intervention }(\$ \mathrm{Am}) \\
\text { Sales } \\
\text { Purchases } \\
\text { Absolute value }\end{array}$ & $\begin{array}{l}46 \\
81 \\
56\end{array}$ & $\begin{array}{r}9 \\
16 \\
14\end{array}$ & $\begin{array}{r}56 \\
100 \\
63\end{array}$ & $\begin{array}{r}35 \\
159 \\
144\end{array}$ & & $\begin{array}{r}36 \\
285 \\
46\end{array}$ \\
\hline $\begin{array}{l}\text { Maximum }(\$ A m) \\
\text { Sale } \\
\text { Purchase }\end{array}$ & $\begin{array}{r}661 \\
1,585\end{array}$ & $\begin{array}{l}44 \\
90\end{array}$ & $\begin{array}{r}661 \\
1,026\end{array}$ & $\begin{array}{r}150 \\
1,305\end{array}$ & $\begin{array}{l}0 \\
0\end{array}$ & $\begin{array}{r}286 \\
1,585\end{array}$ \\
\hline $\begin{array}{l}\text { Memo items }(\$ \mathrm{Am}) \\
\text { Money base } \\
\text { M1 }\end{array}$ & $\begin{array}{l}20,404 \\
60,976\end{array}$ & $\begin{array}{l}11,421 \\
22,831\end{array}$ & $\begin{array}{l}16,206 \\
37,261\end{array}$ & $\begin{array}{l}19,853 \\
57,435\end{array}$ & $\begin{array}{l}22,608 \\
74,242\end{array}$ & $\begin{array}{r}28,995 \\
102,921\end{array}$ \\
\hline
\end{tabular}

Table 2: Comparison of Interventions by Central Banks.

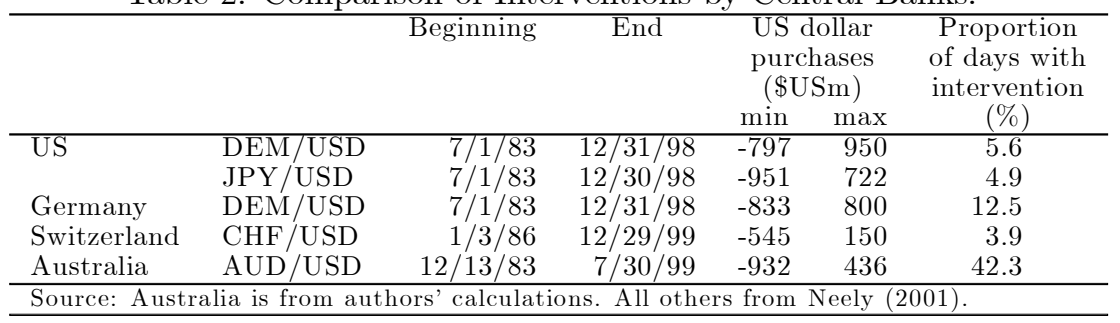


Table 3: EGARCH $(1,1)$ model of Interventions

\begin{tabular}{|c|c|c|c|c|c|c|}
\hline \multirow[b]{2}{*}{ constant } & \multicolumn{2}{|c|}{$\begin{array}{c}\text { Full sample } \\
(7 / 86-11 / 93)\end{array}$} & \multicolumn{2}{|c|}{$\begin{array}{c}\text { Low bound regime } \\
(7 / 86-9 / 91)\end{array}$} & \multicolumn{2}{|c|}{$\begin{array}{c}\text { High bound regime } \\
(10 / 91-11 / 93)\end{array}$} \\
\hline & $\begin{array}{r}0.000 \\
(0.000)\end{array}$ & $\begin{array}{r}0.000 \\
(0.000)\end{array}$ & $\begin{array}{r}0.000 \\
(0.000)\end{array}$ & $\begin{array}{r}0.000 \\
(0.000)\end{array}$ & $\begin{array}{r}0.000 \\
(0.000)\end{array}$ & $\begin{array}{r}0.000 \\
(0.000)\end{array}$ \\
\hline$I N T_{t}$ & $\begin{array}{l}-0.016 \\
(0.001)\end{array}$ & & $\begin{array}{r}-0.020 \\
(0.001)\end{array}$ & & $\begin{array}{l}-0.012 \\
(0.001)\end{array}$ & \\
\hline$I N T_{t-1}$ & $\begin{array}{r}0.004 \\
(0.001)\end{array}$ & $\begin{array}{l}-0.003 \\
(0.001)\end{array}$ & $\begin{array}{r}0.009 \\
(0.002)\end{array}$ & $\begin{array}{r}0.002 \\
(0.002)\end{array}$ & $\begin{array}{r}0.000 \\
(0.001)\end{array}$ & $\begin{array}{r}-0.002 \\
(0.001)\end{array}$ \\
\hline$I N T_{t-2}$ & $\begin{array}{r}0.005 \\
(0.001)\end{array}$ & $\begin{array}{r}0.002 \\
(0.002)\end{array}$ & $\begin{array}{r}0.004 \\
(0.002)\end{array}$ & $\begin{array}{r}0.002 \\
(0.002)\end{array}$ & $\begin{array}{r}0.005 \\
(0.002)\end{array}$ & $\begin{array}{r}0.004 \\
(0.002)\end{array}$ \\
\hline constant & $\begin{array}{l}-0.904 \\
(0.115)\end{array}$ & $\begin{array}{r}-0.807 \\
(0.105)\end{array}$ & $\begin{array}{l}-1.331 \\
(0.164)\end{array}$ & $\begin{array}{l}-1.316 \\
(0.154)\end{array}$ & $\begin{array}{r}-20.122 \\
(0.405)\end{array}$ & $\begin{array}{r}-19.373 \\
(0.667)\end{array}$ \\
\hline$\left|\varepsilon_{t-1} / \sigma_{t-1}\right|$ & $\begin{array}{r}0.286 \\
(0.025)\end{array}$ & $\begin{array}{r}0.250 \\
(0.024)\end{array}$ & $\begin{array}{r}0.349 \\
(0.035)\end{array}$ & $\begin{array}{r}0.333 \\
(0.033)\end{array}$ & $\begin{array}{r}0.166 \\
(0.049)\end{array}$ & $\begin{array}{r}0.213 \\
(0.071)\end{array}$ \\
\hline$\varepsilon_{t-1} / \sigma_{t-1}$ & $\begin{array}{l}-0.053 \\
(0.014)\end{array}$ & $\begin{array}{l}-0.049 \\
(0.012)\end{array}$ & $\begin{array}{r}-0.083 \\
(0.019)\end{array}$ & $\begin{array}{r}-0.085 \\
(0.018)\end{array}$ & $\begin{array}{r}-0.053 \\
(0.021)\end{array}$ & $\begin{array}{l}-0.061 \\
(0.031)\end{array}$ \\
\hline $\log \left(\sigma_{t-1}^{2}\right)$ & $\begin{array}{r}0.934 \\
(0.010)\end{array}$ & $\begin{array}{r}0.940 \\
(0.009)\end{array}$ & $\begin{array}{r}0.896 \\
(0.015)\end{array}$ & $\begin{array}{r}0.895 \\
(0.014)\end{array}$ & $\begin{array}{r}-0.865 \\
(0.038) \\
\end{array}$ & $\begin{array}{r}-0.803 \\
(0.064) \\
\end{array}$ \\
\hline $\begin{array}{l}\text { Model: } \\
\Delta e_{t}=c+\phi \\
\log \left(\sigma_{t}^{2}\right)=u\end{array}$ & $x_{t}$ & $\begin{array}{l}N T_{t-1} \\
1)+\delta\end{array}$ & $\begin{array}{l}N T_{t-2} \\
+\kappa \frac{\varepsilon_{t-1}}{\sigma_{t-}}\end{array}$ & & & \\
\hline
\end{tabular}

Table 4: Estimates of the Standard Model.

\begin{tabular}{|c|c|c|c|c|c|c|c|}
\hline & $\begin{array}{c}\text { Point } \\
\text { Estimate }\end{array}$ & $\begin{array}{c}\text { Mean } \\
\text { Distribution } \\
\end{array}$ & $\begin{array}{l}\text { Standard } \\
\text { Deviation }\end{array}$ & Mean/StDev & Maximum & Minimum & $\begin{array}{c}\text { Percentage } \\
\text { of observations } \\
\text { below zero }\end{array}$ \\
\hline \multicolumn{8}{|c|}{ Exchange rate equation } \\
\hline$\alpha$ & 0.1350 & 0.1364 & 0.0372 & 3.66 & 0.2313 & 0.0332 & $0.0 \%$ \\
\hline$\gamma$ & -0.3042 & -0.3054 & 0.0561 & -5.44 & -0.1457 & -0.4481 & $100.0 \%$ \\
\hline$c_{e}$ & 0.0043 & 0.0078 & 0.0188 & 0.41 & 0.0904 & -0.0859 & $9.9 \%$ \\
\hline \multicolumn{8}{|c|}{ Reaction function } \\
\hline$\beta$ & -0.0279 & -0.0894 & 0.0952 & -0.94 & -0.0047 & -0.5774 & $100.0 \%$ \\
\hline$c_{I N T}$ & -0.0909 & -0.1104 & 0.0552 & -2.00 & 0.0232 & -0.358 & $99.0 \%$ \\
\hline \multicolumn{8}{|c|}{ Other parameters } \\
\hline$\overline{I N T}_{l}$ & 0.3160 & 0.3511 & 0.0869 & 4.04 & 0.9906 & 0.2112 & $0.0 \%$ \\
\hline$\overline{I N T}_{h}$ & 1.8529 & 1.9767 & 1.9874 & 0.99 & 21.6319 & 1.2606 & $0.0 \%$ \\
\hline$\sigma_{\varepsilon}^{2}$ & 0.0345 & 0.0159 & 0.0142 & 1.12 & 0.0383 & 0.0000 & $0.0 \%$ \\
\hline$\sigma_{\eta}^{\tilde{2}}$ & 0.4395 & 0.5025 & 0.1837 & 2.73 & 1.3248 & 0.2381 & $0.0 \%$ \\
\hline$\sigma_{z}^{2}$ & 0.4094 & 0.4562 & 0.1825 & 2.50 & 1.2857 & 0.0652 & $0.0 \%$ \\
\hline
\end{tabular}


Table 5: Estimates of the Model with Lags.

\begin{tabular}{|c|c|c|c|c|c|c|c|}
\hline & $\begin{array}{c}\text { Point } \\
\text { Estimate }\end{array}$ & $\begin{array}{c}\text { Mean } \\
\text { Distribution }\end{array}$ & $\begin{array}{l}\text { Standard } \\
\text { Deviation }\end{array}$ & Mean/StDev & Maximum & Minimum & $\begin{array}{c}\text { Percentage } \\
\text { of observations } \\
\text { below zero }\end{array}$ \\
\hline \multicolumn{8}{|c|}{ Exchange rate equation } \\
\hline$\alpha$ & 0.0446 & 0.0533 & 0.0375 & 1.42 & 0.1579 & 0.0011 & $0.0 \%$ \\
\hline$\gamma$ & -0.0612 & -0.1400 & 0.0844 & -1.66 & 0.0021 & -0.4130 & $99.0 \%$ \\
\hline$\lambda_{e e 1}$ & -0.0638 & -0.0603 & 0.0348 & -1.73 & -0.0263 & -0.3196 & $100.0 \%$ \\
\hline$\lambda_{e e 2}$ & -0.0379 & -0.0385 & 0.0326 & -1.18 & 0.0085 & -0.2962 & $99.0 \%$ \\
\hline$\lambda_{e I N T 1}$ & 0.0369 & -0.0007 & 0.0351 & -0.02 & 0.0866 & -0.0856 & $65.0 \%$ \\
\hline$\lambda_{e I N T 2}$ & 0.0246 & 0.0021 & 0.0321 & 0.07 & 0.1060 & -0.0844 & $57.0 \%$ \\
\hline$c_{e}$ & 0.0004 & 0.0100 & 0.0475 & 0.21 & 0.2608 & -0.1263 & $32.0 \%$ \\
\hline \multicolumn{8}{|c|}{ Reaction function } \\
\hline$\beta$ & -0.0657 & -0.1538 & 0.1142 & -1.35 & 0.0000 & -0.6292 & $100.0 \%$ \\
\hline$\lambda_{I N T e 1}$ & 0.0140 & -0.0184 & 0.0186 & -0.99 & 0.0604 & -0.0742 & $87.0 \%$ \\
\hline$\lambda_{I N T e 2}$ & -0.0030 & -0.0189 & 0.0149 & -1.27 & 0.0760 & -0.0558 & $94.0 \%$ \\
\hline$\lambda_{I N T I N T 1}$ & -0.2299 & -0.0173 & 0.1499 & -0.12 & 0.2819 & -0.6120 & $43.0 \%$ \\
\hline$\lambda_{I N T I N T 2}$ & -0.0923 & -0.0155 & 0.1064 & -0.15 & 0.1913 & -0.3556 & $48.0 \%$ \\
\hline$c_{I N T}$ & -0.0854 & -0.1933 & 0.1150 & -1.68 & 0.0636 & -0.6258 & $98.0 \%$ \\
\hline \multicolumn{8}{|c|}{ Other parameters } \\
\hline$\overline{I N T}_{l}$ & 0.3253 & 0.4194 & 0.1007 & 4.16 & 1.0285 & 0.2500 & $0.0 \%$ \\
\hline$\overline{I N T}_{h}$ & 2.6664 & 1.6935 & 0.4353 & 3.89 & 2.7410 & 0.7022 & $0.0 \%$ \\
\hline$\sigma_{\varepsilon}^{2}$ & 0.0128 & 0.0062 & 0.0046 & 1.36 & 0.0200 & 0.0000 & $0.0 \%$ \\
\hline$\sigma_{\eta}^{2}$ & 0.3423 & 0.6430 & 0.1495 & 4.30 & 0.9579 & 0.2443 & $0.0 \%$ \\
\hline$\sigma_{z}^{2}$ & 0.3044 & 0.4392 & 0.1283 & 3.42 & 0.7659 & 0.0895 & $0.0 \%$ \\
\hline
\end{tabular}




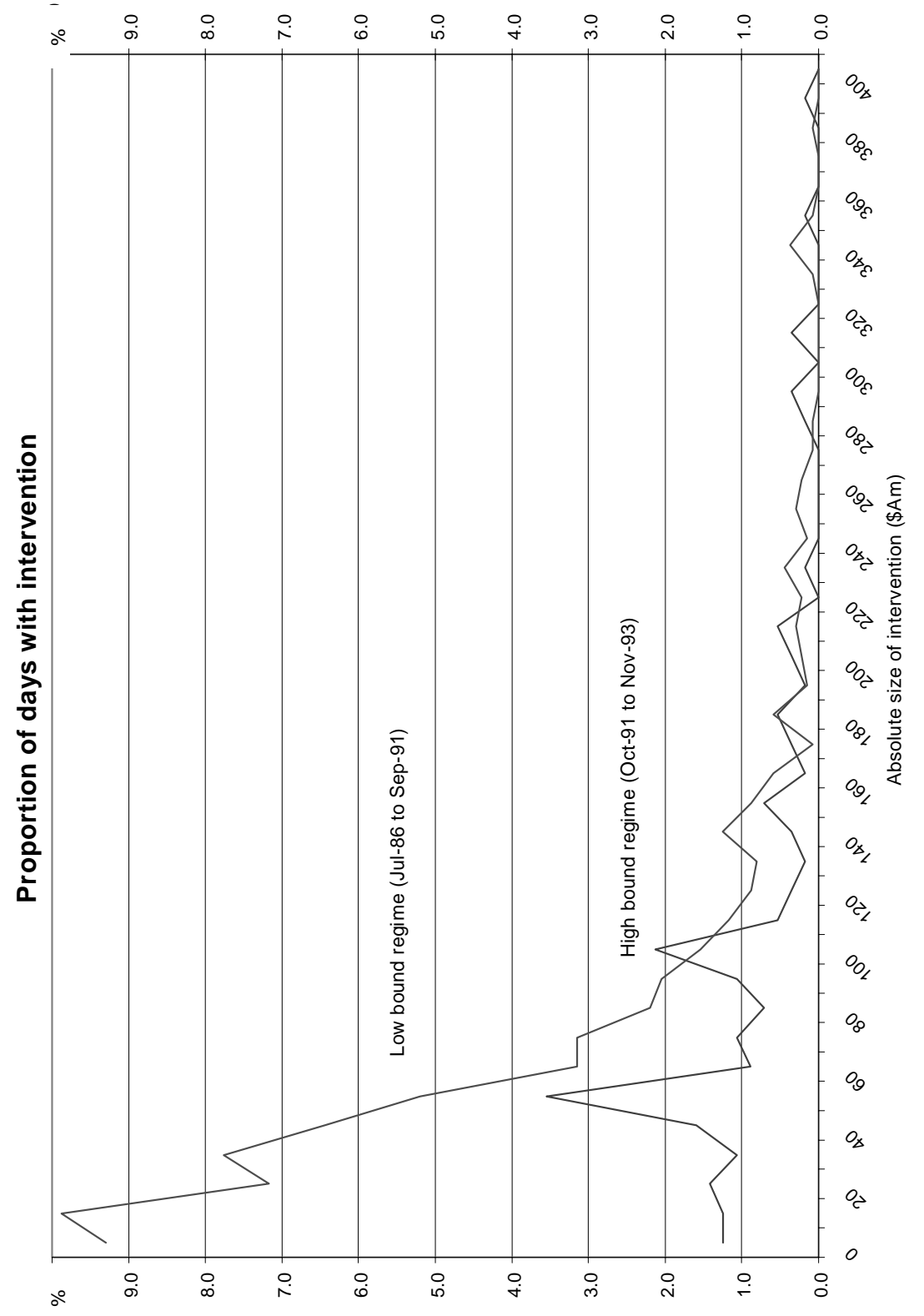

Figure 1: Proportion of days with intervention. 


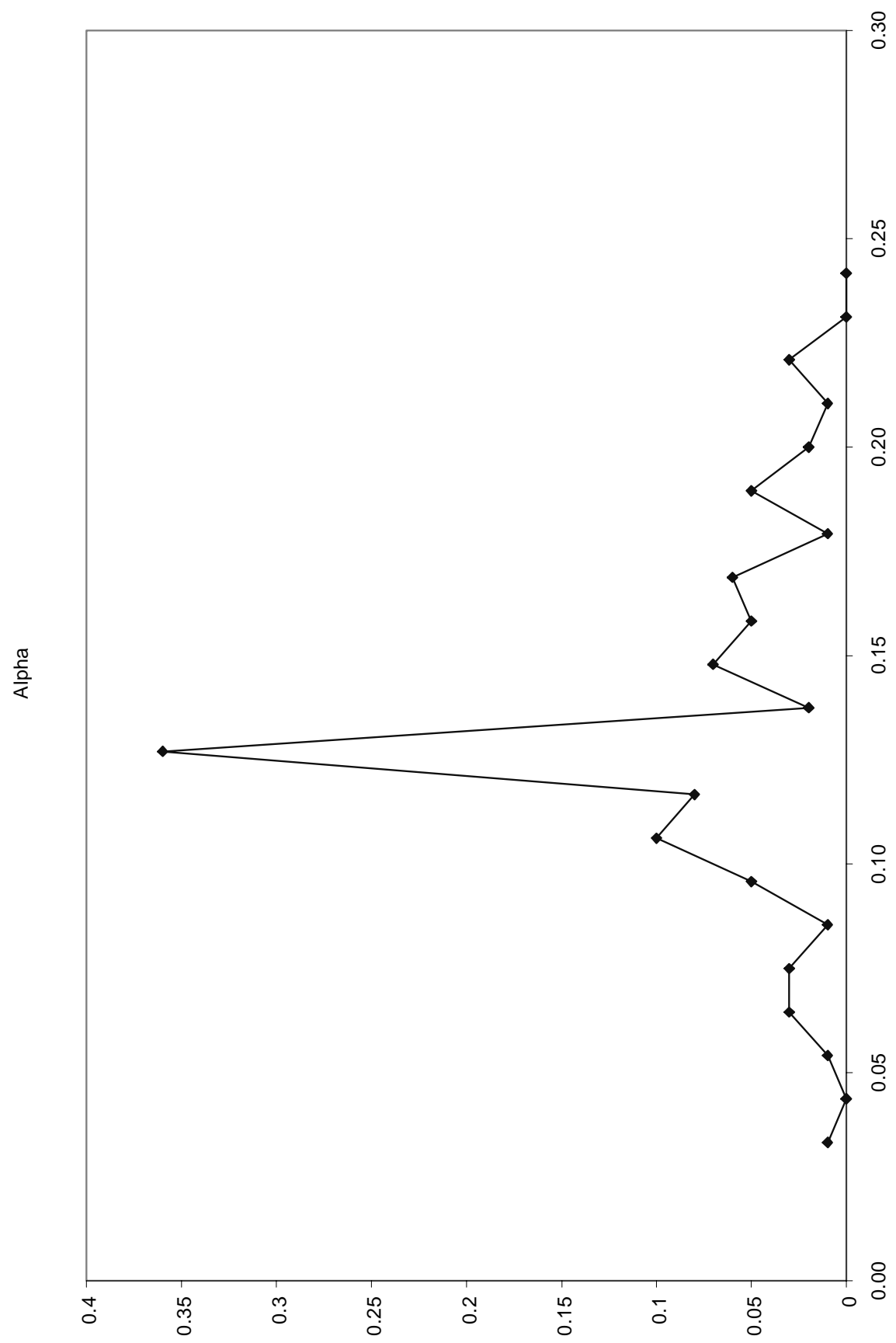

Figure 2: Bootstrapped distribution of $\alpha$ for original model. 


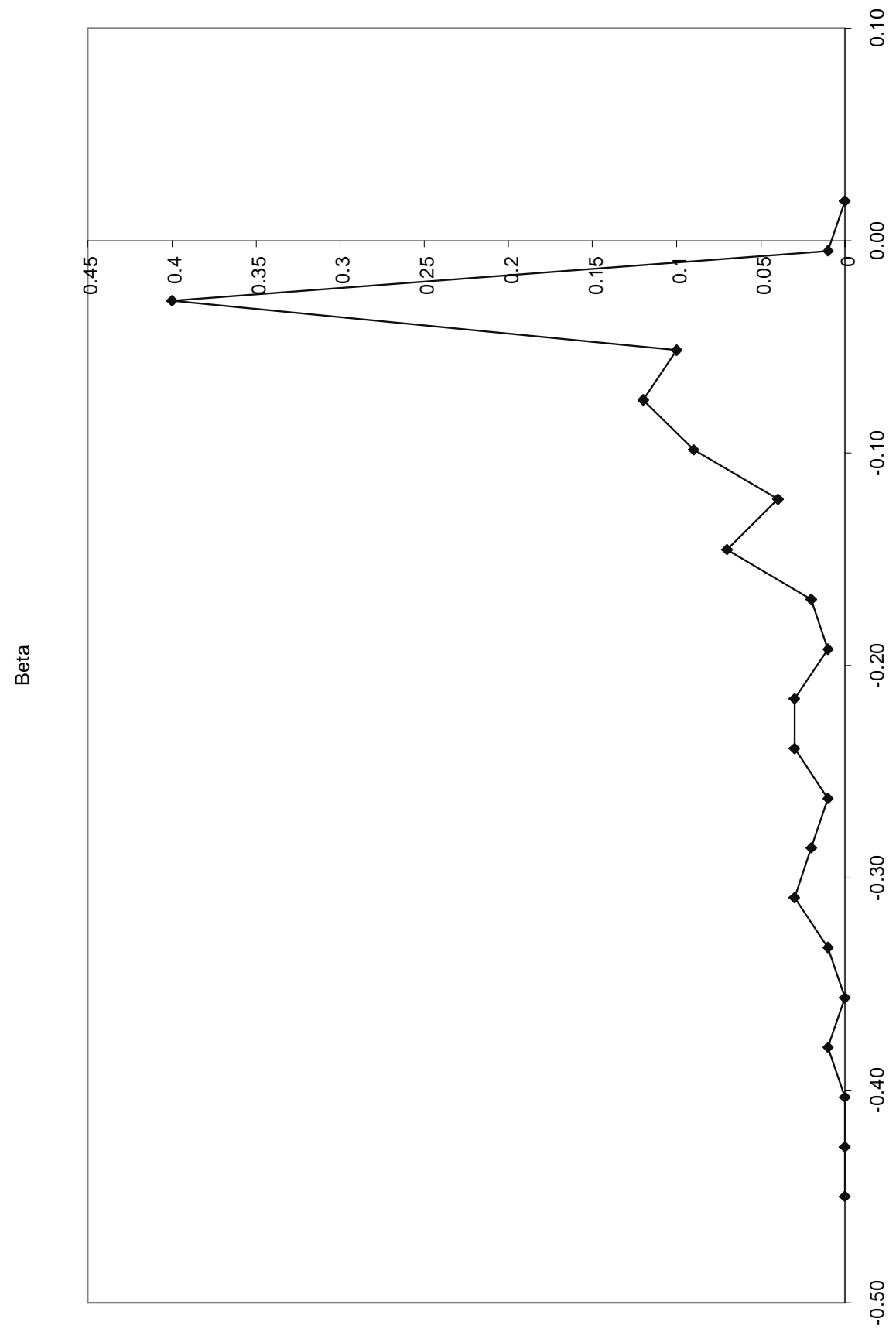

Figure 3: Bootstrapped distribution of $\beta$ for original model. 


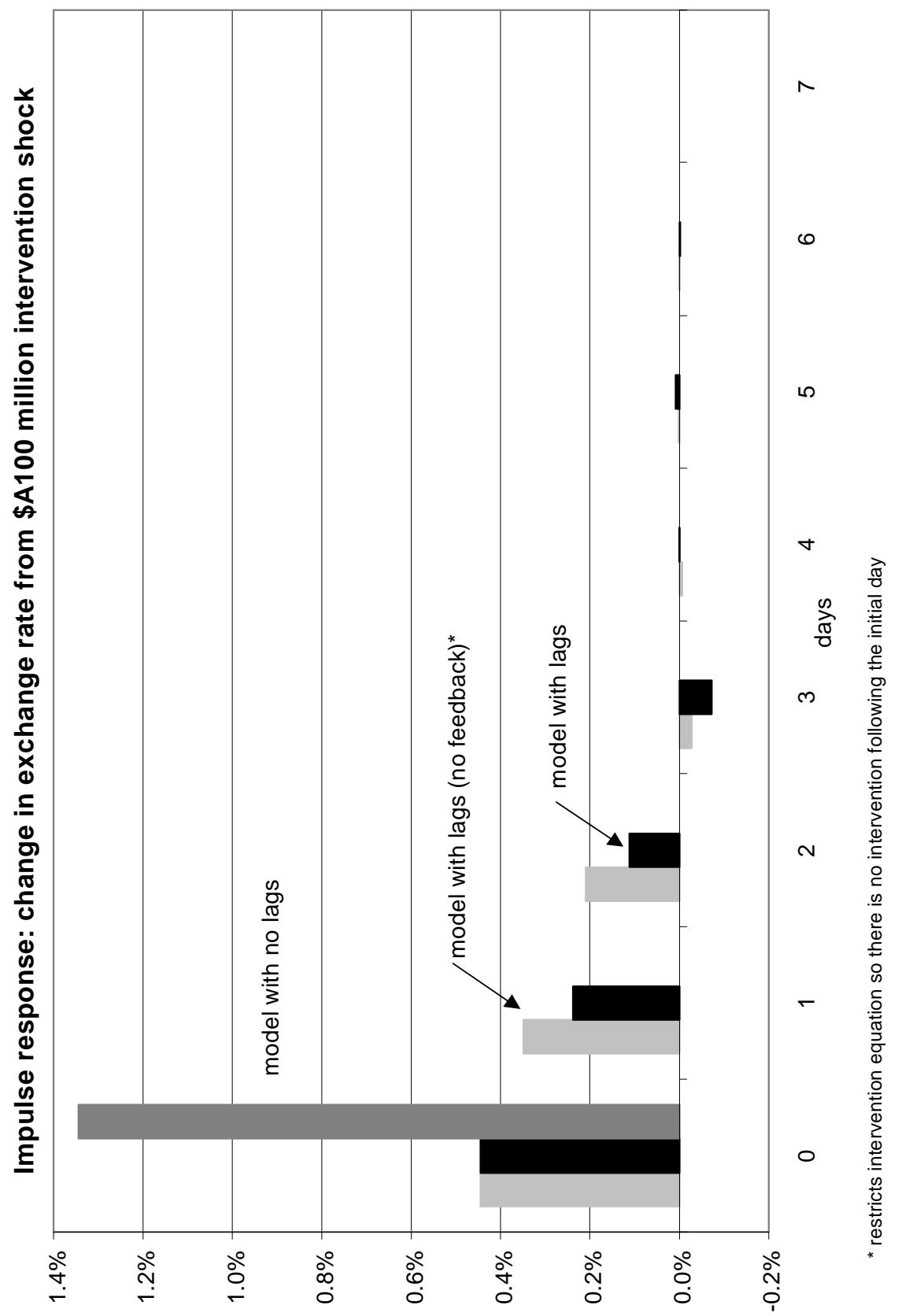

Figure 4: Impulse response: change in exchange rate from $\$$ A100 million intervention shock 


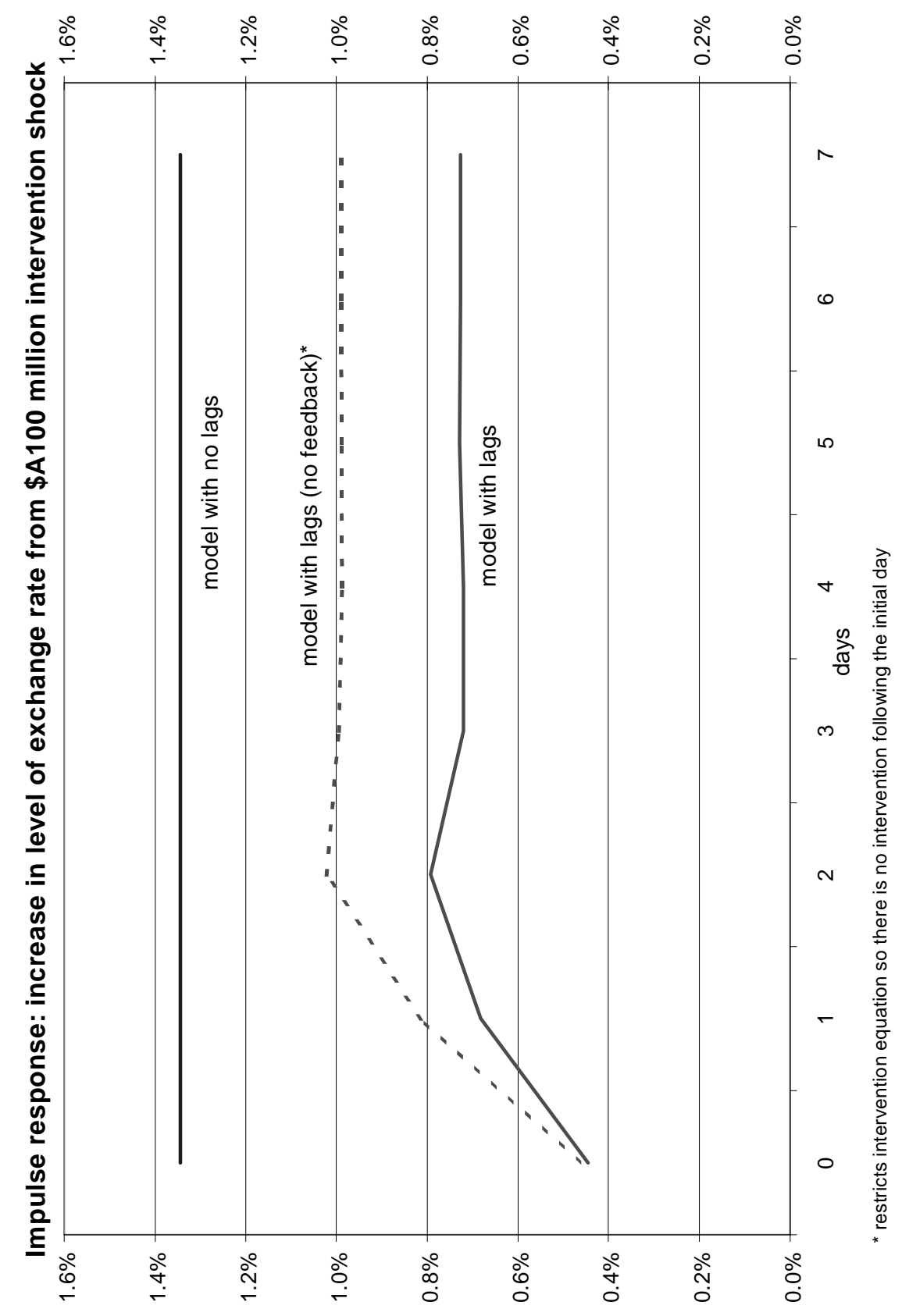

Figure 5: Impulse response: increase in level of exchange rate from $\$ A 100$ million intervention shock 


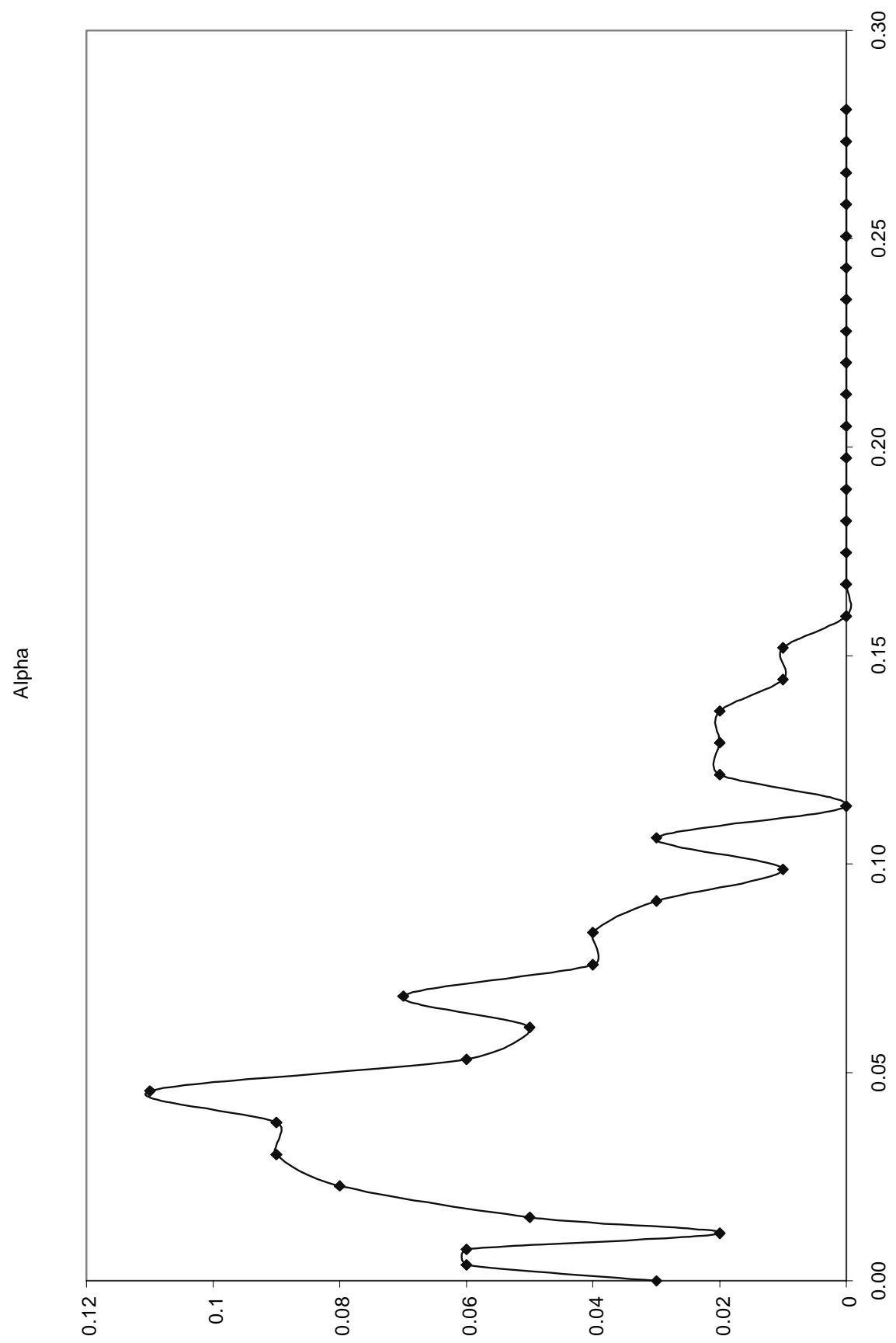

Figure 6: Bootstrapped distribution of $\alpha$ when lags are included in the model. 


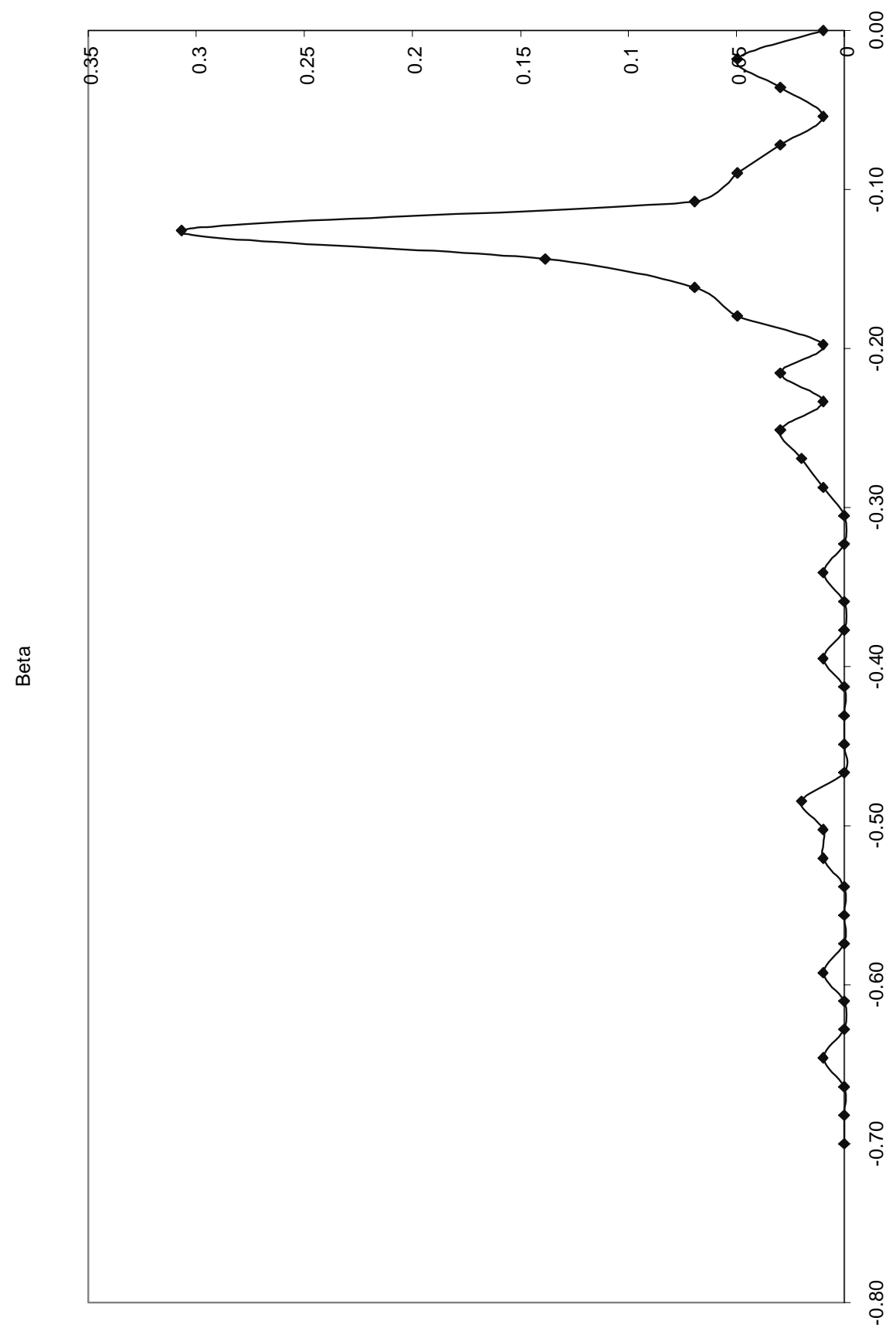

Figure 7: Bootstrapped distribution of $\beta$ when lags are included in the model. 